\title{
ANALISIS PERSEPSI LAYANAN PERBANKAN ELEKTRONIK DIHUBUNGKAN DENGAN FAKTOR KENYAMANAN, KOMUNIKASI DAN KEAMANAN
}

\author{
Ronny \\ Program Studi Magister Manajemen \\ STIE Perbanas Surabaya \\ Jalan Nginden Semolo 34-36, Surabaya
}

\begin{abstract}
Bank in organizing the internet banking service need to pay attention about customer perceptions to perform banking transactions through the website, such as customer perceptions regarding the safety, comfort, and communication. This study is aimed to analyze the customer perceptions on security, convenience, and communication aspects in the transactions use features which available in the banking website. As many as of 56 respondents who use Internet banking have filled out the questionnaire. The Results of study on bank customers responded by 4 bank staffs who understand internet banking. Qualitative analysis of the data has been obtained that the implementation of internet banking services which is reviewed by the safety, comfort, and communications aspects related to 5 main factors: the ability of technology, the ability of human resources bank, communication, internet banking procedures, and customer involvement.
\end{abstract}

\begin{abstract}
ABSTRAK
Bank dalam menyelenggarakan layanan internet banking penting untuk memperhatikan persepsi nasabah dalam melakukan transaksi melalui website perbankan, seperti persepsi nasabah mengenai keamanan, kenyamanan, dan komunikasi. Penelitian ini bertujuan untuk menganalisis persepsi nasabah mengenai aspek keamanan, kenyamanan, dan komunikasi dalam melakukan transaksi mengggunakan fitur yang tersedia dalam website perbankan. Sebanyak 56 responden yang menggunakan internet banking telah mengisi kuesioner. Hasil penelitian pada nasabah bank ditanggapi oleh 4 pegawai bank yang memahami internet banking. Analisis data secara kualitatif telah diperoleh hasil bahwa penyelenggaraan layanan internet banking yang ditinjau dari aspek keamanan, kenyamanan, dan komunikasi berkaitan dengan 5 faktor utama yakni kemampuan teknologi, kemampuan sumber daya manusia bank, komunikasi, prosedur internet banking, dan keterlibatan nasabah.
\end{abstract}

Keywords: internet banking, internet banking adoption, banking websites 


\section{PENDAHULUAN}

Peranan layanan perbankan dalam perekonomian Indonesia sangat penting untuk mendorong pertumbuhan ekonomi. Dalam era perkembangan teknologi informasi saat ini, bank turut memanfaatkan teknologi untuk meningkatkan kualitas layanannya. Salah satu produk teknologi informasi yang memberikan daya tarik bagi industri perbankan adalah internet.

Pemanfaatan internet banking telah meluas penggunaan dan penyelenggaraannya. Manfaat yang diberikan oleh bank dalam layanan internet banking bagi nasabah di antaranya memberikan layanan 24 jam, akses yang mudah dan murah, tersedia berbagai macam fitur, seperti pengecekan saldo, transfer, pembelian pulsa, pemesanan tiket, pembayaran listrik. Manfaat tersebut merupakan daya tarik bagi nasabah untuk menggunakan internet banking.

Transaksi internet banking di Indonesia semakin berkembang dan terus bertambah peminatnya. Demikian pula kompetisi antar bank meningkat dalam memberikan layanan terbaik melalui internet banking. Data topbrand-award.com menunjukkan 4 bank di Indonesia memiliki top brand index tertinggi yakni Klik BCA 53,7\%, internet banking Mandiri 20,2\%, internet banking BRI 10,6\%, dan internet banking BNI 9,6\%.

Tantangan besar bagi industri perbankan di atas berkaitan pula tingginya kompetisi antar bank dalam meningkatkan layanan nasabah, sementara teknologi informasi juga terus berkembang yang banyak memberikan daya tarik, sehingga penggunanya semakin bertambah jumlahnya di dunia, termasuk industri perbankan.
Masalah yang dihadapi oleh penyelenggara internet banking adalah bagaimana memberikan layanan internet banking yang mampu memuaskan kebutuhan dan tuntutan nasabah dalam kenyamanan, keamanan, dan komunikasi layanan, sehingga memberikan nilai kepercayaan (trust) yang mempengaruhi keputusan nasabah untuk mengadopsi dan/atau menggunakan internet banking dari sebuah bank.

Penelitian yang telah dilakukan mengenai aspek kenyamanan, keamanan, dan komunikasi layanan internet banking menggunakan unit analisis meliputi nasabah dan pegawai bank. Karakteristik nasabah yang menjadi target penelitian ini adalah nasabah perorangan. Sedangkan pegawai bank yang dimaksudkan adalah pegawai bank yang mengerti penyelenggaraan internet banking di perbankan. Tujuan menggunakan responden pegawai bank adalah untuk menilai persepsi nasabah, sehingga diperoleh gambaran yang utuh mengenai aspek komunikasi, keamanan, dan kenyamanan dalam penggunaan/penyelenggaraan layanan internet banking.

Dua pokok masalah yang akan dijawab melalui penelitian sebagai berikut: Bagaimana persepsi nasabah mengenai komunikasi, keamanan, dan kenyamanan dalam penggunaan/ adopsi layanan internet banking? Bagaimana persepsi pegawai bank mengenai komunikasi, keamanan, dan kenyamanan dalam penyelenggaraan layanan internet banking?

Tujuan yang diharapkan dari penelitian ini adalah untuk menganalisis persepsi nasabah mengenai komunikasi, keamanan, dan kenyamanan dalam penggunaan layanan internet banking. Untuk menganalisis persepsi pegawai bank mengenai 
komunikasi, keamanan, dan kenyamanan dalam penyelenggaraan layanan internet banking.

\section{TINJAUAN PUSTAKA \\ Keamanan}

Persepsi keamanan adalah faktor penting yang mempengaruhi adopsi internet banking (Nasri, 2011). Bank seharusnya mengelola dan meminimalkan faktor resiko dan faktor gangguan keamanan karena nasabah memiliki ekspetasi internet banking terhindar dari gangguan keamanan. Persepsi keamanan oleh Sanayei and Saneian (2013) digambarkan sebagai penyebab situasi, kondisi, atau kejadian dengan potensi masalah ekonomi untuk sumber daya data dapat mengalami kerusakan, kehancuran, sehingga tidak berguna.

Layanan internet banking seharusnya memberikan kepercayaan yang tinggi bagi konsumen, jika bank mengembangkan keamanan layanan, memproteksi informasi pribadi, memberikan jaminan jika terjadi kegagalan, menurunkan waktu tunda pembayaran (Al-Smadi, 2012). Kepercayaan dan keamanan merupakan prioritas yang tinggi dalam online banking, apalagi nasabah tidak bertatap muka dengan petugas bank. Kesenjangan kepercayaan dapat disebabkan oleh kesenjangan keamanan, reputasi bank yang buruk, atau mungkin teknologi yang buruk. Gupta and Bansal (2012) berpendapat bahwa dimensi keamanan atau dimensi privasi merupakan penentu yang penting dari seluruh kualitas layanan internet banking. Jaminan berarti nasabah merasa aman dalam menggunakan layanan bank (Zarei, 2010). Pendekatan keamanan ini merupakan salah satu faktor penting dalam layanan internet banking.

\section{Kenyamanan}

Persepsi kenyamanan memiliki efek signifikan pada perilaku minat menggunakan online banking (Nasri, 2011). Penelitian Nasri (2011) pada 'early adopters' menunjukkan kenyamanan (convenience) adalah indikator penting dari minat untuk mengadopsi internet banking. Kenyamanan diistilahkan waktu yang terpakai yang berkaitan dengan aksesbilitas.

Pandangan sama berasal dari Lichtenstein dan Williamson (2006) bahwa konsep kenyamanan berkaitan diantaranya istilah aksesbilitas. Kenyamanan dapat pula dikaitkan dengan kemudahan yang dirasakan nasabah ketika menggunakan internet banking.

\section{Komunikasi}

Keamanan penting bagi bank dapat dikembangkan sebagai strategi pemasaran. Bank membutuhkan kemampuan untuk menunjukkan keamanan, keandalan e-banking systems, memproteksi informasi pribadi dan keamanan pada transaksi pembayaran (Nasri, 2011). Strategi pemasaran diantaranya strategi promosi yang berkaitan dengan komunikasi.

Bank seharusnya menggunakan secara efektif media seperti radio, tv, brosur, dan halaman web untuk memperkenalkan internet, melakukan edukasi mengenai bagaimana menjadi pengguna internet banking (Clemes et al., 2012). Bank seharusnya menyampaikan manfaat dan fitur layanan internet banking dalam kampanye pemasaran. Bank seharusnya juga menjelaskan pada nasabah bagaimana website bank terpelihara dengan aman. 
Pendekatan komunikasi mengakibatkan bertambahnya pengetahuan nasabah. Pendekatan pengetahuan, pesan yang meningkatkan kesadaran, dan pendekatan pelatihan penting dalam mendorong adopsi internet banking (Sohrabi et al., 2013). Bank menyelenggarakan kampanye untuk me-ningkatkan kesadaran pada banyak orang (Eze et al., 2011).

Komunikasi membuat nasabah paham mengenai keuntungan yang dapat diperoleh dan perlindungan atau jaminan bank terhadap upaya mencegah gangguan atau serangan terhadap informasi nasabah, sehingga dapat menciptakan kepercayaan yang tinggi pada nasabah.

Menurut Munusamy et al., (2012) bahwa penting mempromosikan penggunaan internet banking. Panduan mengenai bagaimana menggunakan internet banking sebagai fasilitas nasabah. Komunikasi dapat melalui media web perbankan. Website bank seharusnya didesain user friendly, sehingga nasabah dapat banyak waktu digunakan untuk online menggunakan layanan bank (Mahfooz et al., 2013).

Komunikasi nasabah dapat melalui staf bank yang siap ketika dibutuhkan, sehingga akan meningkatkan jumlah nasabah yang menggunakan internet banking (Hassan, 2012). Agar staf bank dapat melayani nasabah dengan baik, diperlukan pelatihan staf bank untuk meningkatkan efesiensi melayani permintaan nasabah (Nimako et al., 2013).

\section{METODE PENELITIAN}

Penelitian yang dilakukan memilih sejumlah responden yakni nasabah dan pegawai bank yang menggunakan/memahami layanan internet banking. Nasabah sebagai responden dipilih untuk mendapatkan gambaran tentang perilaku nasabah dalam menggunakan internet banking sebagai masukan bagi peneliti dalam menganalisis persepsi nasabah yang terlibat dalam layanan internet banking untuk menemukan kesamaan titik temu dengan persepsi pegawai bank.

\section{Sumber Data}

Dalam penelitian ini, jenis dan sumber data yang digunakan adalah data primer yang merupakan data yang didapat dari sumber responden yaitu nasabah dan pegawai bank lewat penyebaran kuesioner.

\section{Penentuan Responden}

Jumlah responden berpatokan pada kecukupan variasi informasi yang dibutuhkan, tidak mengarah pada banyaknya responden yang memberi informasi sebagai generalisasi terhadap populasi. Metode memilih responden yakni teknik snowball.

Dalam penelitian ini, pertimbangan menentukan responden sebagai sumber informasi adalah memenuhi kriteria yakni nasabah yang masih menggunakan internet banking di salah satu atau lebih bank di Indonesia.

Peneliti memilih responden lanjutan untuk mencari tambahan variasi informasi yang mungkin ada. Peneliti dapat menghentikan mencari responden lanjutan ketika sudah tidak ditemukan lagi variasi informasi dari jawaban responden.

Dalam penelitian yang dilakukan digunakan pengumpulan data melalui kuesioner yang dimaksudkan untuk memperoleh gambaran mengenai perilaku responden dalam menggunakan internet banking. 


\section{Analisis Data}

Analisis data dilakukan secara berkelanjutan selama pengumpulan data berlangsung sampai pada akhir penelitian. Semakin banyak variasi informasi diperoleh merupakan target peneliti. Dalam penelitian ini, analisis data dilakukan sejak awal penelitian dan selama proses penelitian dilaksanakan. Ada 4 macam analisis data yang digunakan terdiri atas analisis domain, analisis taksonomi, analisis komponensial, dan analisis tema budaya.

\section{Validitas Temuan}

Agar hasil penelitian memiliki tingkat kepercayaan yang tinggi, maka upaya yang dilakukan sebagai berikut: memperpanjang waktu peneliti dalam proses pengumpulan data; melakukan observasi secara mendalam; melakukan triangulasi sumber data. Untuk triangulasi sumber data, peneliti menggunakan responden dengan latar belakang yang berbeda dari segi pendidikan, pekerjaan, jenis kelamin, dan usia.

\section{Definisi Operasional Variabel}

Definisi operasional masingmasing variabel dijelaskan sebagai berikut:

1. Kenyamanan adalah kemudahan yang dirasakan nasabah dalam menggunakan internet banking, seperti mudah dipelajari, mudah dimengerti, kemudahan dalam dukungan kegiatan transaksi perbankan, kemudahan melakukan transaksi di internet.

2. Keamanan adalah rasa aman yang dirasakan nasabah ketika menggunakan internet banking, seperti penyimpanan data yang akurat, informasi pribadi nasabah ter- simpan aman, peningkatan teknologi keamanan bank.

3. Komunikasi. Respon yang diberikan bank melalui internet banking atas permintaan nasabah misalnya ketika nasabah menghadapi masalah dalam penggunaan online banking terdapat hubungan komunikasi ke staf bank melalui telepon.

\section{HASIL DAN PEMBAHASAN Hasil Penelitian \\ Deskripsi Subjek Penelitian}

Jumlah responden yang digunakan dalam penelitian ini sebanyak 60 responden terdiri atas responden nasabah bank sebanyak 56 nasabah, dan responden karyawan bank sebanyak 4 responden (BRI, CIMB Niaga, dan Danamon). Responden diambil dengan menggunakan purposive sampling, yaitu teknik pengambilan sampel yang dilakukan dengan memilih responden yang memenuhi kriteria yang ditetapkan sesuai dengan tujuan penelitian. Nasabah yang dipilih adalah nasabah yang punya pengalaman menggunakan internet banking > 6 bulan, sedangkan responden dari karyawan bank yang memiliki kompetensi dalam bidang layanan internet banking. Target utama penelitian ini pada nasabah, meskipun demikian responden karyawan bank diperlukan untuk memberikan tanggapan atas persepsi nasabah.

Persepsi Nasabah Mengenai Komunikasi, Keamanan, dan Kenyamanan dalam penggunaan/Adopsi Layanan Internet Banking

\section{Komunikasi}

Komunikasi yang dipersepsikan nasabah dalam layanan internet 
banking adalah bagaimana tampilan website yang komunikatif, dan ketersediaan petugas bank 24 jam yang dapat dihubungi ketika nasabah ingin menanyakan suatu hal atau menghadapi masalah penggunaan internet banking. Selain itu, nasabah mengharapkan sosialisasi penggunaan internet banking ditingkatkan.

Tampilan website yang lebih komunikatif bertujuan agar mudah dipelajari, mudah digunakan, lebih menarik tampilannya sehingga pengguna dapat optimal menggunakan fitur yang tersedia dan kebutuhan nasabah dapat dipenuhi dalam transaksi keuangan melalui jalur online.

Nasabah menginginkan tersedianya petugas bank setiap waktu dapat ditanyai masalah penggunaan internet banking. Petugas bank yang mudah dihubungi dengan waktu tunggu yang singkat dan jumlah petugas yang memadai, jika perlu menambah jumlah petugas call center. Pendapat nasabah tersebut berkaitan dengan pemenuhan kebutuhan rasa aman dan jaminan layanan penyelesaian masalah yang cepat, sehingga dapat menimbulkan kepercayaan nasabah.

Nasabah mempersepsikan layanan internet banking berkaitan dengan layanan konvensional, bank perlu menyediakan customer service khusus internet banking atau ada online messanger ketika sudah login pada website perbankan, call center 24 jam. Keinginan nasabah ini dimaksudkan agar penggunaan internet banking optimal dan terpercaya. Online messanger memungkinkan nasabah langsung dapat melakukan chat dengan petugas bank jika menemui kendala penggunaan web perbankan.

Tabel 1

Komposisi Responden

\begin{tabular}{|c|c|c|c|}
\hline Item & Skala & $\begin{array}{l}\text { Jumlah } \\
\text { Responden }\end{array}$ & Prosentase \\
\hline \multirow[t]{4}{*}{ Usia } & $19-25$ thn & 14 & $25.00 \%$ \\
\hline & $26-31$ & 20 & $35.71 \%$ \\
\hline & $32-37$ & 14 & $25.00 \%$ \\
\hline & $>37$ & 8 & $14.29 \%$ \\
\hline \multirow{4}{*}{$\begin{array}{l}\text { Pendidikan } \\
\text { Terakhir }\end{array}$} & SMA & 13 & $23.21 \%$ \\
\hline & Diploma & 4 & $7.14 \%$ \\
\hline & $\mathrm{S} 1$ & 35 & $62.50 \%$ \\
\hline & $\mathrm{S} 2$ & 4 & $7.14 \%$ \\
\hline \multirow[t]{5}{*}{ Pekerjaan } & Pegawai Negeri & 3 & $5.36 \%$ \\
\hline & Pegawai Swasta & 34 & $60.71 \%$ \\
\hline & Wiraswasta & 9 & $16.07 \%$ \\
\hline & Pelajar/Mhs & 5 & $8.93 \%$ \\
\hline & Lain-lain & 5 & $8.93 \%$ \\
\hline \multirow{3}{*}{$\begin{array}{l}\text { Lama } \\
\text { menggunakan } \\
\text { internet }\end{array}$} & $>2$ thn & 25 & $44.64 \%$ \\
\hline & $1-2$ thn & 14 & $25.00 \%$ \\
\hline & 6 bln $-<1$ thn & 17 & $30.36 \%$ \\
\hline
\end{tabular}


Sosialisasi penggunaan internet banking dapat mendorong nasabah lebih efektif dan optimal menggunakan internet banking. Bank seharusnya melakukan sosialisasi ini secara berkelanjutan. Sosialisasi ini termasuk pula tentang keamanan layanan yang selama ini menjadi perhatian serius bagi nasabah. Konsep pengembangan layanan internet banking tidak saja pada pengembangan website, tetapi bagaimana website bank dapat digunakan dengan mudah dan memiliki informasi bantuan yang mudah didapatkan dan dipelajari, memberi penjelasan tentang alur transaksi.

\section{Keamanan}

Nasabah mempersepsikan keamanan merupakan faktor penting dalam layanan internet banking karena tatap muka tidak dengan petugas bank. Kepercayaan terletak pada fungsi keamanan yang baik. Nasabah menilai keamanan yang baik ketika kurangnya atau tidak ada keluhan atas kegagalan atau kekacauan transaksi. Bank punya prosedur keamanan yang jelas dan meningkatkan terus keamanan internet banking yang dapat dirasakan oleh nasabah. Setiap transaksi melalui verifikasi dari nasabah.

Bank harus meningkatkan keamanan internet banking, dengan prosedur keamanan yang tidak rumit, meningkatkan up date sistem keamanannya, memperketat setiap transaksi dengan password atau pin. Harapan nasabah agar bank memperkecil banyaknya kasus dan keluhan dari nasabah.

Rasa aman yang diberikan melalui layanan bank perlu dikomunikasikan dengan nasabah agar kepercayaan nasabah meningkat bahwa layanan yang digunakan terproteksi dari hacker jahat. Dengan setiap transaksi harus ada verifikasi dari nasabah, atau menyediakan alat khusus untuk akses semacam token yang meyakinkan nasabah atas keamanan internet banking.

\section{Kenyamanan}

Nasabah mempersepsikan kenyamanan sebagai kemudahan menggunakan internet banking yang berkaitan dengan koneksi internet, fitur yang mudah dipelajari dan digunakan, prosedur penggunaan yang tidak rumit.

Akses berkaitan dengan koneksi yang bagus, akses yang cepat, mudah mengakses web dengan berbagai perangkat komputer. Koneksi yang bagus dipersepsikan nasabah sebagai koneksi yang tidak mudah putus karena akan menganggu transaksi. Akses yang cepat dimaksudkan sebagai respon yang cepat ketika memilih fitur. Nasabah juga mengharapkan website bank dapat diakses dengan berbagai jenis perangkat teknologi, sehingga perbedaan alat yang digunakan nasabah tidak menjadi masalah untuk mengakses internet banking.

Prosedur layanan yang tidak rumit, mudah dipelajari, mudah dipilih, dibutuhkan kejelasan informasi di web bank, sehingga nasabah mendapatkan informasi yang jelas tentang prosedur penggunaan internet banking.

\section{Persepsi Karyawan Bank Mengenai} Komunikasi, Keamanan, dan Kenyamanan dalam Penyelenggaraan Layanan Internet Banking

\section{Komunikasi}

Komunikasi yang dipersepsikan karyawan bank dalam penyelenggaraan layanan internet banking ada- 
lah akses yang cepat dimaksudkan sebagai respon yang cepat ketika memilih fitur, mudah dalam menggunakan internet banking, dan desain website yang menarik/komunikatif.

Karyawan bank mempersepsikan sama dengan nasabah bank bahwa penting petugas customer service dan call center dalam memberikan bantuan berupa penyampaian informasi atau solusi jika nasabah menghadapi masalah. Layanan call center 24 jam yang bebas pulsa dan mudah dihubungi, dan tersedia online messanger ketika nasabah login. Perlunya customer service mengedukasi penggunaan E-banking.

Peran customer service di setiap kantor cabang bank menawarkan sosialisasi e-banking kepada nasabah setelah mengakhiri pelayanan nasabah. Petugas customer service dan call center perlu memiliki pengetahuan tentang penggunaan internet banking, sehingga dapat membantu nasabah bila ada keluhan.

\section{Keamanan}

Karyawan bank mempersepsikan keamanan dalam layanan internet banking sebagai hal yang sangat penting. Bahwa nasabah menganggap penting keamanan internet banking merupakan hal yang wajar, mengingat maraknya kasus penipuan yang menggunakan sistem internet banking. Akan tetapi bank sebagai pemilik produk internet banking pastinya telah berupaya membuat sistem keamanan internet banking yang baik. Keamanan internet banking tidak hanya menjadi tanggung jawab bank sebagai penyedia sarana transaksi real time ini, nasabah pun sebagai penggunanya harus memiliki kesadaran dalam menjaga data keuangannya di sistem internet banking. Hal yang bisa dilakukan adalah secara berkala mengganti pasword internet banking, segera menghapus token yang masih tersisa dan yang sudah digunakan, pastikan bertransaksi pada halaman (website) yang benar, dan melakukan logout jika telah selesai.

Keamanan dalam penyelenggaraan layanan internet banking perlu dikomunikasikan dengan nasabah agar kepercayaan nasabah meningkat, bahwa layanan yang digunakan terproteksi dari hacker jahat. Setiap transaksi harus ada verifikasi dari user atau menyediakan nasabah menggunakan alat khusus untuk akses semacam token yang meyakinkan nasabah atas transaksi $e$-banking yang dilakukannya. Termasuk ada tambahan fitur personal sistem saat nasabah login dan sebelum melakukan transaksi, dan perbankan harus selalu meng-update sistem keamanan $e$-banking-nya.

\section{Kenyamanan}

Karyawan bank mempersepsikan kenyamanan penyelenggaraan layanan internet banking sebagai kemudahan yang bisa dirasakan nasabah seperti prosedur layanan yang tidak rumit, mudah dipelajari, mudah dipilih. Akses yang cepat memberikan kenyamanan pada nasabah seperti desain website perbankan yang minimalis tetapi tidak meninggalkan keindahan dan ciri khas suatu bank, sehingga jutaan nasabah mampu mengakses setiap hari tanpa down server.

Sosialisasi tentang kenyamanan kepada nasabah menjadi penting, misalnya nasabah perlu disosialisasikan jangka waktu penggunaan akses e-banking, karena jika tidak beraktivitas dalam jumlah menit tertentu, sistem keamanan akan otomatis melakukan log out. 
Kenyamanan dalam kemudahan mengakses internet banking bank melalui berbagai perangkat teknologi dipersepsikan oleh karyawan bank sebagai kemudahan yang perlu ditunjang dengan spesifikasi perangkat yang sudah memadai. Perbankan meluncurkan aplikasi e-banking yang dapat digunakan secara praktis misalnya pada smartphone, diikuti dengan melakukan pembaharuan aplikasi e-banking mobile dalam sisi keamanan dan kemudahan penggunaan.

\section{Pembahasan}

Persepsi nasabah dan karyawan bank pada dasarnya memiliki titik temu yang dapat dianalisis ke dalam 5 faktor, yakni kemampuan teknologi, kapasitas sumber daya manusia bank, komunikasi, prosedur, dan keterlibatan nasabah yang dapat dijelaskan sebagai berikut:

\section{a) Kemampuan teknologi}

Teknologi merupakan kekuatan utama dalam layanan internet banking, karena transaksi yang dilakukan nasabah melalui penggunaan teknologi berbasis web. Nasabah tidak bertemu secara nyata dengan petugas bank, tetapi melalui informasi dan menu instruksi dalam website perbankan. Website perbankan berperan sebagai customer service yang melayani kebutuhan transaksi melalui berbagai fitur.

Persepsi nasabah terhadap kemampuan teknologi mengedepankan dukungan terhadap kemampuan teknologi yang aman, layanan internet banking yang mudah dipelajari dan digunakan, sehingga dapat menimbulkan kenyamanan dan rasa aman.

\section{b) Kapasitas SDM Bank}

Ketersediaan petugas bank yang memiliki pengetahuan yang memadai mengenai layanan internet banking yang mampu menjalankan fungsi edukasi/sosialisasi menyampaikan informasi dan atau solusi atas keluhan nasabah atau keingintahuan nasabah mengenai fitur-fitur yang tersedia dalam web perbankan, sehingga optimalisasi penggunaan internet banking dapat tercapai.

Kemampuan SDM Bank terutama customer service dan call center yang cukup dari segi kuantitas dan kualitas. Jumlah petugas bank yang cukup melayani nasabah melalui layanan call center, sehingga nasabah tidak harus menunggu lama ketika menghubungi call center. Dari segi kualitas, kecakapan petugas call center melayani nasabah. Kecakapan ini ditunjang dengan pengetahuan yang memadai.

\section{c) Komunikasi}

Aspek komunikasi yang diharapkan nasabah adalah kedekatan nasabah dengan petugas bank yang melayani setiap hari (24 jam) atau setiap saat dibutuhkan baik melalui call center, customer service, maupun petugas yang online di web perbankan (online messanger) bisa melakukan chat, sehingga tiap saat nasabah ingin bertanya tentang penggunaan atau masalah penggunaan internet banking dapat dibantu dengan solusi yang tepat.

Komunikasi yang berjalan dengan baik dapat meningkatkan kepercayaan nasabah terutama tentang keamanan transaksi. Kegiatan edukasi/ sosialisasi memberikan pemahaman kepada nasabah tentang bagaimana seharusnya menggunakan internet banking yang aman seperti peran serta nasabah untuk ikut menjaga kerahasiaan password web dan memeliharanya misalnya secara berkala nasabah melakukan pergantian password. 


\section{d) Prosedur}

Keamanan yang diharapkan nasabah ditunjang dengan prosedur keamanan yang tersedia. Dengan demikian, ketika ada persoalan gangguan keamanan, maka baik nasabah maupun pihak bank dapat mengenali prosedur keamanan yang terselenggara. Prosedur atau rule yang ada juga menyangkut bagaimana kesederhanaan prosedur alur transaksi dalam penggunaan internet banking, karena nasabah menilai prosedur yang berbelit-belit seperti prosedur keamanan yang rumit akan menimbulkan ketidaknyamanan atau kebosanan. Sebab prosedur keamanan yang terlalu kompleks akan menimbulkan pula tingkat kapasitas bandwidth yang meningkat yang dimaknai oleh nasabah sebagai loading web yang lambat.

\section{e) Keterlibatan Nasabah}

Keterlibatan nasabah diperlukan untuk berperan aktif dalam verifikasi setiap transaksi untuk mengamankan transaksi dari dua belah pihak bukan saja dari perbankan tapi juga dari nasabah. Verifikasi yang dimaksud misalnya nasabah dikirimkan token berupa kode yang harus di-input ke dalam web untuk memastikan bahwa pihak yang akan melakukan transaksi adalah pihak nasabah yang sah.

\section{KESIMPULAN}

Nasabah mempersepsikan bahwa komunikasi didasarkan pada dua hal yakni kemampuan website dan ketersediaan petugas bank dari segi kuantitas maupun kualitas. Dari segi kemampuan website, yakni informasi dan fitur yang komunikatif, mudah dipahami dan digunakan. Dari segi kualitas yakni ketersediaan petugas bank yang memadai pengetahuan dan jumlahnya.
Nasabah mempersepsikan keamanan perlu ditingkatkan terus tetapi prosedur keamanan yang tidak kompleks sehingga tingkat keluhan rendah.

Nasabah mempersepsikan kenyamanan sebagai kemudahan menggunakan internet banking, mudah dipelajari dan mudah digunakan, web perbankan yang dapat berjalan pada tingkat bandwidth yang rendah di berbagai perangkat teknologi.

Karyawan bank setuju dengan persepsi nasabah tentang keamanan, komunikasi, dan kenyamanan dengan mengedepankan pentingnya keterlibatan nasabah ikut serta menjaga keamanan dalam melakukan transaksi melalui layanan internet banking.

Lima faktor yang menjadi titik temu antara persepsi nasabah dan persepsi karyawan bank adalah faktor keamanan, kapasitas SDM bank, komunikasi, prosedur, dan keterlibatan nasabah.

\section{SARAN}

Bank perlu melakukan edukasi atau sosialisasi tentang jaminan keamanan untuk menciptakan kepercayaan nasabah. Selain itu, respon komunikasi perlu ditata lebih baik lagi agar nasabah mendapatkan informasi yang detil dan jelas. Komunikasi juga harus dibangun pada level call center, sehingga diperlukan call center yang memadai dari segi kuantitas maupun kualitas.

Kenyamanan merupakan perasaan senang yang dirasakan nasabah atas pengalaman menggunakan internet banking yang berkaitan dengan kecepatan layanan. Bank perlu meningkatkan kenyamanan agar nasabah merasakan kemudahan dengan efesiensi prosedur yang sederhana, serta akses web perbankan yang cepat. 
Analisis Persepsi Layanan Perbankan Elektronik Difubungkan dengan Faktor Kenyamanan,

Komunikasi dan Keamanan

\section{DAFTAR KEPUSTAKAAN}

Al-Smadi, Mohammad O., 2012, Factors Affecting Adoption of Electronic Banking: An Analysis of the Perspectives of Banks' Customers, International Journal of Business and Social Science, Vol. 3, No. 17, page 294-309.

Clemes, Michael D, Christopher Gan and Junhua Du, 2012, The Factors Impacting on Customers' Decisions to Adopt Internet Banking, Journal of Bank and Bank System, Vol. 7, Issue 3, page 33-50.

Eze, Uchenna Cyril, Jeniffer Keru Manyeki, Ling Heng Yaw, and Lee Chai Har, 2011, Factors Affecting Internet Banking Adoption among Young Adults: Evidence from Malaysia, International Conference on Social Science and Humanity IPEDR, Vol.5, page 377-381.

Gupta, Kamal K. and Ipshita Bansal, 2012, Internet Banking Service Quality in India. International Refered Research Journal, Vol. III, Issue 2(2), page 11-25.

Hassan, M. Taimoor, 2012, Customer Service Quality Perception of Internet Banking, International Journal of Learning \& Development, Vol. 2, No. 2.

Lichtenstein, Sharman and Kirsty Williamson, 2006, Understanding Consumer Adoption of Internet Banking: An Interpretive Study in the Australian Banking Context, Journal of Electronic Commerce Research Vol. 7, No. 2, page 5066.
Mahfooz, Yasser, Mohammad AlMotairi, Farah Ahmad and Altaf Khan, 2013, A Study of the Service Quality Issues of Internet Banking in Non-Metro Cities of India, Journal of Advanced Management Science, Vol. 1, No. 1, page 75-79.

Munusamy, Jayarama, Sanmugam Annamalah, and Shankar Chelliah, 2012, A Study of Users and Non-users of Internet Banking in Malaysia, International Journal of Innovation, Management and Technology, Vol. 3, No. 4, page $452-458$.

Nasri, Wadie, 2011, Factors Influencing the Adoption of Internet Banking in Tunisia, International Journal of Business and Management, Published by Canadian Center of Science and Education, Vol. 6, No. 8, page 143-160.

Nimako, Simon Gyasi, Nana Kwame Gyamfi, Abdil Mumuni Moro Wandaogou, 2013, Customer Satisfaction With Internet Banking Service Quality In The Ghanaian Banking Industry, International Journal of Scientific \& Technology Research Vol. 2, Issue 7, page 165-175.

Sanayei, Ali and Zahra Sadat Saneian, 2013, Analysis of Traditional Attributes and Website Attributes in Order to Improve Customers Trust in Electronic Banking, International Journal of Academic Research in Business and Social Sciences, Vol. 3, No. 11, page 7689. 
Analisis Persepsi Layanan Perbankan Elektronik Dihubungkan dengan Faktor Kenyamanan, Komunikasi dan Keamanan

Sohrabi, Maryam, Julie Yew Mei Yee, Robert Jeyakumar Nathan, 2013, Critical Success Factors for the Adoption of e-Banking in Malaysia, International Arab Journal of e-Technology, Vol. 3, No. 2, page 76-82.
Zarei, Shapoor, 2010, Electronic Service Quality Evaluation Methods for Online-Banking System, IJCST, Vol. 1, Issue 2, page 6-13. 